\title{
Importance of Prompt Diagnosis in the Management of Colonoscopic Perforation
}

\author{
In Ja Park \\ Department of Colon and Rectal Surgery, Asan Medical Center, University of Ulsan College of Medicine, Seoul, Korea
}

\section{See Article on Page 228-231}

Colonoscopy is a commonly-performed procedure for the diagnosis, treatment, and surveillance of colorectal disease. Transient gastrointestinal symptoms after colonoscopy have been reported in up to one-third of the patients, but serious complications are uncommon. The incidence of perforation is reported to range from $0.003 \%$ to $0.8 \%$ for diagnostic colonoscopy and from $0.15 \%$ to $3 \%$ for therapeutic colonoscopy. The authors of the present study reported a $0.3 \%$ incidence of perforation from colonoscopy, which is an acceptable rate [1].

Colonoscopic perforation is associated with high morbidity and mortality, with estimated 30-day morbidity and mortality rates of $21 \%-53 \%$ and $0 \%-26 \%$, respectively. Therefore, prompt diagnosis and optimal treatment are common $[2,3]$. Colonoscopic perforations may be managed operatively or conservatively. Conservative treatment includes bowel rest, intravenous fluids, and antibiotics to limit peritonitis and to allow the perforation to seal. Several large studies have reported that many patients with perforations may be conservatively treated with success. Factors to consider in therapeutic decision making are the degree of peritoneal contamination, which depends on the type of perforation mechanism, the colonic preparation for the colonoscopy, and the interval between the diagnosis and the treatment [4].

The surgical procedures include primary repair, resection, and anastomosis or colostomy. The specific operative procedures used will depend on the size of perforation, the degree of peritoneal

Correspondence to: In Ja Park, M.D.

Department of Colon and Rectal Surgery, Asan Medical Center, University of Ulsan College of Medicine, 88 Olympic-ro 43-gil, Songpa-gu,

Seoul 138-736, Korea

Tel: +82-2-3010-3937, Fax: +82-2-474-6027

E-mail: ipark@amc.seoul.kr

(C) 2014 The Korean Society of Coloproctology

This is an open-access article distributed under the terms of the Creative Commons Attribution NonCommercial License (http://creativecommons.org/licenses/by-nc/3.0) which permits unrestricted noncommercial use, distribution, and reproduction in any medium, provided the original work is properly cited. soilage, the presence of an associated colonic pathology, the stability of the patient, and the overall underlying condition of the patient. Many studies have emphasized that prompt diagnosis is one of the most important prognostic factors after colonoscopic perforation because the severity of peritoneal contamination depends on the duration of contamination, as well as the size of perforation. A recent study of 165 patients with a colonoscopic perforation showed that patients presenting after 24 hours were more likely to have feculent contamination $(\mathrm{P}=0.02)$ and to need a stoma than patients presenting earlier $(P=0.02)$. The study also demonstrated that morbidity was nearly twice as high in patients presenting after 24 hours, although that finding was not statistically significant. If peritoneal soilage is significant, a major operation, such as a bowel resection or a colostomy, will be required [5].

The authors of "Prompt Management is Most Important for Colon Perforation After Colostomy" focused on operation type according to the timing of the diagnosis [6]. As we expected, a major operation was done much more frequently for patients who were diagnosed with a perforation longer than 24 hours after the colonoscopy. Although those authors showed an association of operation type with prompt diagnosis of a colonoscopic perforation, factors that may been related to the treatment method for a colonoscopic perforation were not analyzed. Other than the timing of the diagnosis, bowel preparation status, medical comorbidities of the patients, and the size of the treated polyp/mass in the case of a therapeutic colonoscopy will also affect the severity of a colonoscopy-associated perforation. In terms of operative type, the authors categorize colonoscopic clip application and primary closure (laparotomy or laparoscopy) into the same category. I think these types of treatments should be classified differently because primary closure needs both general anesthesia and surgery, which have the potential to do more harm than colonoscopic intervention.

The most common site of a colonoscopic perforation has been reported to be the sigmoid colon. Therefore, trying to locate the perforation site by using an air leak test, which the authors describe in their "DISCUSSION" section, may be useful in many cases, but the ability of the air leak test to locate the perforation may be limited, depending on the site of the perforation. Perforations that oc- 
cur in the proximal colon are difficult to detect by using this method.

Although a couple of issues with respect to this topic remain to be considered, the authors of this study collected and analyzed medical information on consecutive cases at a single institution. Based on the results of this study, the time between the colonoscopy and the diagnosis is one of the most important factors that determine the type of treatment and the prognosis.

\section{REFERENCES}

1. Ko CW, Dominitz JA. Complications of colonoscopy: magnitude and management. Gastrointest Endosc Clin N Am 2010;20:65971.

2. Castellvi J, Pi F, Sueiras A, Vallet J, Bollo J, Tomas A, et al. Colonoscopic perforation: useful parameters for early diagnosis and conservative treatment. Int J Colorectal Dis 2011;26:1183-90.

3. Teoh AY, Poon CM, Lee JF, Leong HT, Ng SS, Sung JJ, et al. Outcomes and predictors of mortality and stoma formation in surgical management of colonoscopic perforations: a multicenter review. Arch Surg 2009;144:9-13.

4. La Torre M, Velluti F, Giuliani G, Di Giulio E, Ziparo V, La Torre F. Promptness of diagnosis is the main prognostic factor after colonoscopic perforation. Colorectal Dis 2012;14:e23-6.

5. Iqbal CW, Cullinane DC, Schiller HJ, Sawyer MD, Zietlow SP, Farley DR. Surgical management and outcomes of 165 colonoscopic perforations from a single institution. Arch Surg 2008;143: 701-6.

6. Kim HH, Kye BH, Kim HJ, Cho HM. Prompt management is most important for colon perforation after colonoscopy. Ann Coloproctol 2014;30:228-31. 